
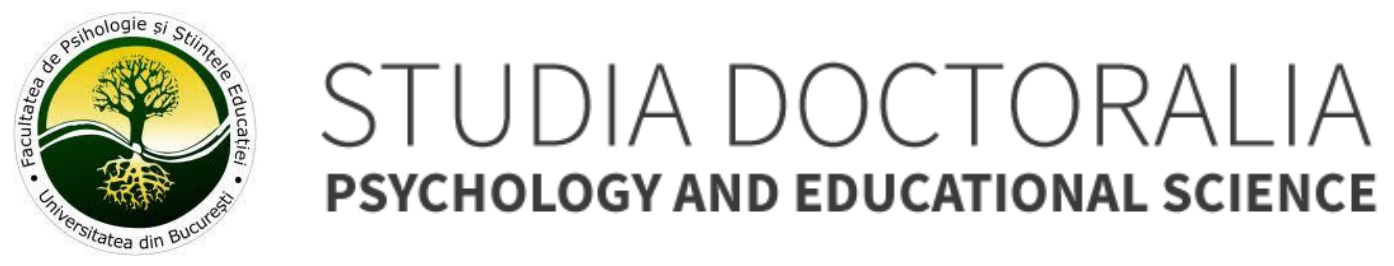

PSYCHOLOGY AND EDUCATIONAL SCIENCE

\title{
EDITORIAL
}

\section{Communicating through the pandemic}

\author{
Ștefania Chihaia \\ https://doi.org/10.47040/sd/sdpsych.v11i2.112
}

How do we live? How do we communicate? The same; yet, differently. Friends and loved ones are still available to us from one digital screen away. Things we consume through the media, through virtual communication, is equally accessible. But this accessibility comes at a price: a hidden danger ready to tangle us in webs of hysteria, misinformation, and superficial connection, all of which comes to light by the hands of the coronavirus, and its pervasive presence in each aspect of our lives. All this creates a rupture through a fragile ecosystem; it seems ruthless, when, in reality, it is only about natural evolution (the spread of a virus via a global infrastructure) and, in the face of this threat throughout this crisis, the adaptation of human society and its way of relating via communication. We see a veil lifted over the landscape of the modern world, a world undergoing an old crisis on a new scale. In view of the shortcomings, flaws, deficiencies, and imbalances discovered, I hope that you will allow me to outline a psychic image of the world - of Romania in the bosom of the world - these days.

Children, the young, the elderly, the nurses and the unemployed, the judges and the criminals: we are all navigating these new realities though some kind of simultaneous stagnasis and change. We are experiencing a stage of dehumanisation in a form that we, ourselves, have never before encountered, but which was known to previous generations during the pandemics that have ravaged the world's population since the 5 th century BC. Some of us do not view COVID as a real threat to our health, favoring so-called conspiracy theories, while there are others of us who are frightened. And while, for some, the beginning of quarantine has generated anxiety, for others, the pandemic has triggered or amplified graver diseases of mental health. Many experts, psychologists and psychiatrists both, argue that the pandemic's impact on mental health is likely to extend over a much longer period of time than its impact on physical health.

It is communication, in particular, that changes its form, in all of its dimensions, as we adapt to its strengths as well as its challenges. The restrictions preventing normal socialisation are manifested through the loss of rituals, the interruption of the natural cycle and flow of life with its varied events. Let of recall, for a moment, children's joy through moments of free play and socialisation (moments replaced with online school and an increasing addiction to digital stimuli); highschool's friendships; first dates (now online); spontaneous manifestations of energy and affection; birthday celebrations; funeral ceremonies; traditions and habits of a folk, cultural, or religious nature. Tangled in this web of restraints, it is difficult to express some of our thoughts and emotions unrestrained; instead, we supress our daily feelings. We hit brick walls in our freedom of physical movement, as well as our communication.

Let us look to our fears: we could catch the virus from anywhere, anyhow. The field in which we live our lives 
demands our acute awareness to the potential dangers and sources of nervousness, tension, uncertainty surrounding us. Dozens, hundreds of daily unconscious gestures ask, all at once, to be monitored - such as holding a support bar in public transporation, effecting a payment at the grocery store -, taking up emotional and cognitive space which we usually devote to other purposes. These days, many of us are wondering: Did I expose myself today? Will I expose someone else? It is not only the responsibility for our own health that we carry, but also that of those around us. These matters deprive us of our total capacity as capable conduits for communication forms, be these words, facts, or choices.

By hindering the freedom of movement and exploration craved by childhood, the pandemic diminishes children's opportunities for spontaneity and creativity, just as it deprives older people of the warmth of their loved ones. All of these lacks, and of many more kinds, highlight the negative impact this pandemic has upon mental health. We can talk about the alteration of psychological developmental stages of children and adolescents, wherein social relationships are a crucial factor in the formation of the personality; what occurs is a frustration of normal needs of relating and exploring that facilitate psychic development. Imagine young university students returning to their parents' homes because the Universities of Bucharest, ClujNapoca, etc. conduct their classes online. To indulge in a metaphor, the communication network emotional, intellectual, pragmatic - necessary for individuation is largely reduced to virtual interaction. Can the mind and body feed on this, or is it a state of subsistence, temporary as it may be, that affects future generations?

Lovers, families, those who live together are walking through a test of fire. Communication varies and fluctuates due to the countless factors that destabilise the psyche and its ability to rationalise. Consequently, we are faced with some choices: to communicate openly or with hostility, to manage our difficulties and emotional processes consciously - opening up to ourselves, to the other - or to keep them in check, for fear that we won't be able to cope with the complexity of the situation, or for fear of being overwhelmed.

And here we are, at the last form of communication as ritual: our farewell from those of us who passed away as a result of the infection. There are people - wife, brother, father, child - who cannot say goodbye to their loved ones: they do not follow the natural course of mourning, the psychic significance of the ceremony that marks the loss.

We gather our information from the online medium, consuming sensationalist representations of reality, exhausting to the mind and the body. This triggers in us a paradoxical dependence on a continuous flow of information that does not, in fact, guarantee the veracity of its myriad stories. The accumulated frustration, tension and fear owed to the insecurity of tomorrow, the effect of the herd mentality, bring discordance and imbalance in our lives in these times, when we do not have the certainty of the truth and its origin. We are facing an overload of our capabilities for managing risk and change, individually and collectively: contradicting facts, inconclusive or contradictory studies, fanaticism and paranoia, unconscious transmission of unverified information that influences our actions and choices, resentments, resignation, and revolts against perceived violation of our right to freedom.

In the whirlwind of innumerable uncertainties and crumbs of truth communicated through each channel, we look helplessly at the seedling sprouted from the seed, planted from the beginning of time: the fact that we are not masters of our own lives. We live in a divided field, where forms of communication and information transmitted by institutions, authorities, and (unknown) virtual sources make us vulnerable to false preaching and manipulation, instigating social division and feeding general inculture.

Through it all, we have this vital need to communicate without words, bodily: to share expressions and meanings intimately. And in twelve months, everything has come undone as we are adapting to the flow of events. In the midst of all these emotions, can we stop? To express our feelings, to live with compromises, losses - the constant change that life always is, which the pandemic has, once again, made clear? Any ecosystem, adapting to change, becomes even stronger, more integrated and resilient. Even if we cannot always identify change in real time, it always unfolds. Maybe all this is, in fact, a challenge that requires our awareness and the development of our communication skills. Perhaps it is not all about a dehumanisation; perhaps we can also talk about a rehumanisation. 